Jurnal Kesmas Asclepius

Volume 2, Nomor 1, Juni 2020

e-ISSN: 2684-8287

p-ISSN: 2656-8926

DOI: https://doi.org/10.31539/jka.v2i1.1145

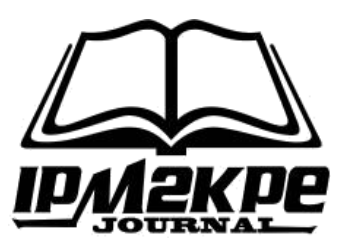

\title{
PENGETAHUAN DAN PENDAPATAN AKSEPTOR KB DENGAN PENGGUNAAN ALAT KONTRASEPSI BAWAH KULIT (AKBK)
}

\author{
Lia Hartini \\ Dinas Pengendalian Penduduk dan Keluarga Berencana \\ liahartini65@gmail.com
}

\begin{abstract}
ABSTRAK
Tujuan penelitian ini untuk mengetahui hubungan pengetahuan dan pendapatan akseptor KB dengan alat kontrasepsi bawah kulit (AKBK) di BPM Habibah Kelurahan Mesat Jaya Tahun 2020. Metode penelitian menggunakan metode survey analitik dengan pendekatan cross sectional. Hasil analisis univariat didapatkan dari 50 responden diketahui sebagian besar responden berpengetahuan baik sebanyak 28 responden $(56 \%)$ lebih banyak dari yang berpengetahuan kurang yaitu sebanyak 22 responden (44\%), sebagian kecil responden yang mempunyai pendapatan tinggi sebanyak 19 responden (38\%) lebih sedikit dari ibu yang berpendapatan rendah 32 responden (62\%) dan yang menggunakan Alat Kontrasepsi Bawah Kulit (AKBK) sebanyak 35 (70\%) responden. Berdasarkan hasil uji statistik chi square pada hubungan antara pengetahuan ( $\rho$ value $0,011)$ dan pendapatan ( $\rho$ value 0,042 ) dengan pemakaian AKBK. Simpulan, ada hubungan yang bermakna antara hubungan pengetahuan dan pendapatan dengan penggunaan alat kontrasepsi bawah kulit (AKBK) di BPM Habiba Kelurahan Mesat Jaya Tahun 2020.
\end{abstract}

Kata Kunci : Akseptor KB, Alat Kontrasepsi Pengetahuan, Pendapatan

\begin{abstract}
This study aimed to determine the relationship between knowledge and income of family planning acceptors and subcutaneous contraception (AKBK) at BPM Habibah, Meat Jaya Village, in 2020. The research method used an analytic survey method with a Cross-Sectional approach. Univariate analysis results obtained from 50 respondents known that most respondents with good knowledge as many as 28 respondents (56\%) more than those who lack awareness that is as much as 22 respondents (44\%), a small proportion of respondents who have high incomes are 19 respondents (38\%) more few of the low-income mothers were 32 respondents (62\%). Those using under-skin contraception (AKBK) were $35(70 \%)$ respondents. Based on the chi-square statistical test results on the relationship between knowledge ( $\rho$ value 0.011) and income ( $\rho$ value $0.042)$ with the use of $A K B K$. In conclusion, there is a significant relationship between knowledge and income with the use of under-the-skin contraception (AKBK) at BPM Habiba, Meat Jaya Urban Village, in 2020.
\end{abstract}

Keywords: Family Planning Acceptor, Knowledge Contraception, Income 


\section{PENDAHULUAN}

Keluarga Berencana adalah tindakan yang membantu individu atau pasangan untuk mendapatkan objektif tertentu, menghindari kelahiran yang tidak diinginkan, mengatur diantara kehamilan, mengontrol waktu saat kelahiran (Hartanto, 2010). Tujuan keluarga berencana membentuk keluarga kecil sesuai dengan kekuatan sosial ekonomi suatu keluarga dengan cara mengatur kelahiran anak agar diperoleh suatu keluarga yang bahagia dan sejahtera yang dapat memenuhi kebutuhan hidupnya (Hartono, 2010; Kusmiran, 2012).

Indonesia merupakan negara berkembang yang memiliki masalah dalam jumlah penduduk. Dari hasil sensus tahun 2015 Indonesia merupakan peringkat keempat dunia, jumlah penduduk Indonesia sebanyak 237.641.326 jiwa dengan kenaikan 1,49 \% tiap tahunnya (Badan Pusat Statistik, 2015). Masalah pokok di bidang kependudukan yang muncul adalah jumlah penduduk besar dengan laju pertumbuhan penduduk yang relatif tinggi, penyebaran penduduk yang tidak merata, struktur penduduk muda, kualitas penduduk yang masih harus ditingkatkan (Septianingrum, et al., 2018).

Pembangunan bangsa adalah membangun Indonesia seutuhnya, yaitu manusia yang takwa terhadap Tuhan Yang Maha Esa, dapat hidup selaras dan seimbang dengan sesama manusia dan dapat menghargai lingkungan sebagai tempat seluruh kehidupan. Hanya dengan keluarga kecil semua dapat terwujud, karena keluarga merupakan unit terkecil kehidupan bangsa. Kemampuan penyelenggara pelayanan kesehatan suatu bangsa diluar dengan menentukan tinggi rendahnya angka kematian ibu dan perinatal dalam 100.000 persalinan hidup, sedangkan tingkat kesejahteraan suatu bangsa ditentukan dengan seberapa jauh gerakan keluarga berencana dapat diterima dimasyarakat (Manuaba \& Ida, 2011). Dapat disimpulkan bahwa keluarga berencana adalah suatu upaya pengaturan kelahiran melibatkan peran serta masyarakat dengan menggunakan metode kontrasepsi untuk meningkatkan kesejahteraan keluarga dan mewujudkan keluarga kecil, bahagia dan sejahtera.

Tahun 2019 merupakan tahun terakhir dari Rencana Pembangunan Jangka Menegah Nasional (RPJMN) dan Rencana Strategi (Renstra) BKKBN 2015-2019. Sasaran Badan Kependudukan dan Keluarga Berencana Nasional (BKKBN) ialah : 1). Menurunnya angka kelahiran total (Total FertilityRate/TFR) menjadi 2,28 per wanita, 2). Meningkatnya prevalensi kontrasepsi (Contraceptive Prevalensi Rate / CPR) sebesar $61,3 \%, 3$ ). Menurunnya kebutuhan ber KB yang tidak terpenuhi (unmetneed) sebesar $9,91 \%$, 4). Meningkatnya peserta KB Aktif yang menggunakan Metode Kontrasepsi Jangka Panjang (MKJP) sebesar 23,50 serta 5). Meningkatnya tingkat putus pakai kontrasepsi sebesar 24,6\% (BKKBN, 2020).

Terkait sasaran di atas, hasil capaian BKKBN cukup menggembirakan. Berdasarkan hasil SDKI 2017, Angka Kelahiran Total (TFR) turun dari 2,6 anak dari SDKI 2012 menjadi 2,4 anak per wanita. Angka kelahiran menurut kelompok umur (ASFR) 15-19 mengalami penurunan dari 48 (SDKI 2012) menjadi 36 pada SDKI 2017. Pemakaian kontrasepsi semua cara juga mengalami peningkatan dari 62\% (SDKI 2012) menjadi 64\% (SDKI 2017). Persentase kebutuhan ber KB yang tidak terpenuhi (unmetneed) mengalami penurunan dari 11,4 pada SDKI 2012 menjadi 10,6\% pada (SDKI 2017).

Berdasarkan dari data Dinas PP dan KB Kota Lubuklinggau Tahun 2019 Penggunaan kontrasepsi implant menduduki tingkat ke tiga yaitu sebesar 8.226 atau (186,06\%), suntik 15.414 (97,66\%), pil KB 8.367 (249,76\%), kondom 2.705 (609,23\%), 
IUD 1.312 (194,65\%), MOW 936 (302,91\%) dan kontrasepsi MOP sebesar 204 (145,71\%) dengan jumlah PUS sebesar 47.754 yang menjadi peserta KB aktif sebanyak 37.164 atau $(77,82 \%)$. Sedangkan dengan jumlah akseptor AKBK sebanyak 8.226.

AHULUAN Implant / Alat Kontrasepsi Bawah Kulit (AKBK) merupakan salah satu kontrasepsi hormonal dengan Metode Kontrasepsi Jangka Panjang (MJKP) yang memiliki daya guna yang tinggi, dengan tingkat keberhasilan 97,99\%, dengan berjangka waktu pemakaian 2-5 tahun, dimasukkan dibawah kulit pada lengan kiri atau kanan bagian atas terutama pada lengan yang tidak dominan, berkasiat langsung setelah pemasangan, dan tingkat kesuburan atau fertilitas akan segera kembali segera setelah pencabutannya. Terdapat 3 jenis implant yang sering dikenal, yakni norplant, implanon, dan jedena (Anggraini \& Martini, 2012).

Masa subur adalah suatu masa dalam siklus menstruasi perempuan dimana terdapat sel telur yang matang dan siap dibuahi, sehingga bila perempuan tersebut melakukan hubungan seksual maka kemungkinan kehamilan (Ambarwati, 2011). Masa subur wanita disebut juga masa dimana waktu keluarnya sel telur (umumnya bagi yang mempunyai siklus haid 28-30 hari berada antara hari ke 12 hingga ke 18 dihitung dari haid pertama) (Padila, 2015).

Dari hasil penelitian Caruso et al., (2012) didapatkan 31 wanita usia subur, 25 diantaranya melaporkan kehamilan yang tidak terkontrol dan merasa kurang nyaman dalam jumlah anak yang banyak, sedangkan 6 diantaranya tidak melaporkan kehamilannya. Menurut penelitain Neri et al., (2017) efek kontrasepsi yang sangat baik dengan keamanan dan akseptabilitas, terutama dalam hubungan dengan pemeliharaan kualitas hidup yang baik, seksualitas dan penurunan desminore. Keluarga Berencana (KB) merupakan salah satu program pelayanan kesehatan preventif paling berperan dalam pengendalian pertumbuhan jumlah penduduk sehingga dapat meningkatkan kesehatan dan kesejahteraan bagi keluarga (Prastika et al., 2019).

\section{METODE PENELITIAN}

Jenis Penelitian merupakan cara yang akan dilakukan dalam proses penelitian. Metode penelitian ini harus diuraikan secara rinci seperti variabel penelitian, rancangan penelitian, teknik pengumpulan data, analisis data, cara penafsiran dan penyimpulan hasil penelitian. Metode penlitian ini menggunakan metode survey analitik melalui pendekatan cross sectional dimana variabel independen (pengetahuan dan pendapatan) dan variabel dependen (penggunaan alat kontrasepsi bawah kulit) akan dilakukan secara bersamaan.

Populasi dalam penelitian ini semua ibu yang yang menggunakan alat kontrasepsi yang berkunjung di BPM Habibah Kelurahan Mesat Jaya pada bulan Maret tahun 2020 sebanyak 200 akseptor yang melakukan KB aktif. Sampel adalah objek yang diteliti dan dianggap mewakili seluruh populasi sebanyak $50 \mathrm{ibu}$. Cara pengambilan sampel menggunakan teknik accidental sampling, dimana sampel diambil dari responden atau kasus yang kebetulan ada disuatu tempat atau keadaan tertentu. Peneliti melakukan penelitian dari tanggal 01 sampai dengan 30 Maret 2020 dan dapat digunakan sebagai sampel, bila orang yang kebetulan ditemui itu cocok sebagai sumber data.

Sedangkan kriteria sampel adalah bersedia menjadi responden (bisa membaca dan menulis) dan sebagai akseptor KB yang berkunjung di BPM Habibah Kelurahan Mesat Jaya. Pengambilan data terhadap sampel penelitian dilakukan oleh peneliti dengan cara wawancara dan lembar pertanyaan. Adapun sumber data adalah 1). Data primer yaitu dengan cara wawancara dan lembar pertanyaan yang diperoleh langsung melalui 
wawancara langsung dengan menggunakan lembar pertanyaan atau kuesioner yang diberikan kepada responden, 2). Data sekunder adalah data yang diperoleh dari suatu lembaga atau instansi. Data sekunder diperoleh dari catatan buku register KB di Bidan Praktek Mandiri (BPM) Habiba, internet, buku kesehatan, buku umum yang berkaitan dengan judul penelitian.

Adapun teknik analis data yang digunakan adalah analisis univariat dan analisis bivariat. Analisis univariat dilakukan terhadap tiap variabel dari hasil penelitian. Penelitian ini menggunakan analisis univariat pada variabel independent (pengetahuan dan pendapatan) dengan variabel dependen (alat kontrasepsi bawah kulit). Sedangkan analisis bivariat dilakukan terhadap dua variabel yang diduga berhubungan atau korelasi. Analisis bivariat bertujuan untuk melihat hubungan antara variabel independen yaitu pengetahuan dan pendapatan, dengan variabel dependen yaitu (penggunaan alat kontrasepsi bawah kulit) yang dianalisis dengan uji statistik chi-square dengan derajat kemaknaan $\alpha=0,05$. Bila $\rho$ (value) $\square=\leq 0,05$ maka secara statistik disebut bermakna, maka ada hubungan antara pengetahuan dan pendapatan dengan penggunaan alat kontrasepsi bawah kulit. Jika $\rho$ (value) $\square=>0,05$ maka secara statistik disebut tidak bermakna, maka tidak ada hubungan antara pengetahuan dan pendapatan dengan penggunaan alat kontrasepsi bawah kulit.

\section{HASIL PENELITIAN}

Tabel.1

Distribusi Frekuensi

Pemakaian AKBK

\begin{tabular}{cccccc}
\hline & & Frequency & Percent & Valid Percent & $\begin{array}{c}\text { Cumulatif } \\
\text { Percent }\end{array}$ \\
\hline Valid & Ya & 35 & 70.0 & 70.0 & 70.0 \\
& Tidak & 15 & 30.0 & 30.0 & 100.0 \\
\hline & Total & 50 & 100.0 & 100.0 & \\
\hline
\end{tabular}

Berdasarkan tabel 1 dapat diketahui bahwa dari sebanyak 50 responden mayoritas yang menggunakan kontrasepsi AKBK sebanyak 35 responden (70\%).

Tabel. 2

Distribusi Frekuensi Responden

Berdasarkan Pengetahuan

\begin{tabular}{llllll}
\hline & & Frequency & Percent & $\begin{array}{r}\text { Valid } \\
\text { Percent }\end{array}$ & $\begin{array}{c}\text { Cumulatif } \\
\text { Percent }\end{array}$ \\
\hline \multirow{2}{*}{ Valid } & Baik & 28 & 56.0 & 56.0 & 56.0 \\
& Kurang & 22 & 44.0 & 44.0 & 100.0 \\
\hline & Total & 50 & 100.0 & 100.0 & \\
\hline
\end{tabular}

Berdasarkan tabel 2 dapat diketahui dari 50 responden mayoritas dengan pengetahuan baik sebanyak 28 responden (56\%). 
Tabel.3

Distribusi Frekuensi Responden Berdasarkan Pendapatan

\begin{tabular}{llllll}
\hline & & Frequency & Percent & Valid Percent & $\begin{array}{c}\text { Cumulatif } \\
\text { Percent }\end{array}$ \\
\hline \multirow{2}{*}{ Valid } & Tinggi & 19 & 38.0 & 38.0 & 38.0 \\
& Rendah & 31 & 62.0 & 62.0 & 100.0 \\
& Total & 50 & 100.0 & 100.0 & \\
\hline
\end{tabular}

Berdasarkan tabel 3 dapat diketahui dari 50 responden mayoritas dengan pendapatan rendah sebanyak 31 responden $(62 \%)$.

Tabel. 4

Hubungan antara Pengetahuan Responden dengan Pemakaian AKBK

\begin{tabular}{|c|c|c|c|c|c|c|c|}
\hline \multirow{3}{*}{ Pengetahuan } & \multicolumn{4}{|c|}{ Pemakaian AKDR } & \multirow{2}{*}{\multicolumn{2}{|c|}{ Total }} & \multirow{3}{*}{$P$ Value } \\
\hline & \multicolumn{2}{|r|}{ Ya } & \multicolumn{2}{|c|}{ Tidak } & & & \\
\hline & $\mathrm{N}$ & $\%$ & $\mathrm{~N}$ & $\%$ & $\mathrm{~N}$ & $\%$ & \\
\hline Baik & 15 & $53,6 \%$ & 13 & $46,4 \%$ & 28 & 100 & 0.011 \\
\hline Kurang & 20 & $90,9 \%$ & 2 & $9,1 \%$ & 22 & 100 & \\
\hline Jumlah & 35 & $70,0 \%$ & 15 & $30,0 \%$ & 50 & 100 & \\
\hline
\end{tabular}

Berdasarkan tabel 4 memperlihatkan bahwa ibu yang menggunakan Alat Kontrasepsi Bawah Kulit (AKBK) dengan pengetahuan baik sebesar 15 ibu (53,6\%) dan pengetahuan kurang sebesar 20 responden (90,9\%). Dari hasi uji chi-square di peroleh $\rho$ value $0,011<0,05$. Hal ini menunjukkan adanya hubungan bermakna antara pengetahuan dengan pemakaian AKBK. Dengan demikian hipotesis awal yang menyatakan bahwa ada hubungan yang bermakna antara pengetahuan ibu dengan pemakaian AKBK terbukti secara statistik.

Tabel. 5

Hubungan antara Pendapatan Ibu dengan Pemakaian AKBK

\begin{tabular}{|c|c|c|c|c|c|c|c|}
\hline \multirow{3}{*}{ Pendapatan } & \multicolumn{4}{|c|}{ Suntik } & \multirow{2}{*}{\multicolumn{2}{|c|}{ Total }} & \multirow{3}{*}{$\begin{array}{c}\mathrm{P} \\
\text { Value }\end{array}$} \\
\hline & \multicolumn{2}{|c|}{$\mathrm{Ya}$} & \multicolumn{2}{|c|}{ Tidak } & & & \\
\hline & $\mathrm{N}$ & $\%$ & $\mathrm{~N}$ & $\%$ & $\mathrm{~N}$ & $\%$ & \\
\hline Tinggi & 17 & $89,5 \%$ & 2 & $10,5 \%$ & 19 & 100 & \multirow{3}{*}{0,042} \\
\hline Rendah & 18 & $58,1 \%$ & 13 & $41,9 \%$ & 31 & 100 & \\
\hline Jumlah & 35 & $70,0 \%$ & 15 & $30,0 \%$ & 50 & 100 & \\
\hline
\end{tabular}

Berdasarkan tabel 5 memperlihatkan bahwa responden yang menggunakan Alat Kontrasepsi Bawah Kulit (AKBK) dengan pendapatan tinggi sebesar 17 responden $(89,5 \%)$ dan responden dengan pendapatan rendah sebesar 18 responden $(58,1 \%)$.Hasil Uji Statistik diperoleh $\rho$ value $0,042<\square 0,05$. Hal ini menunjukkan adanya hubungan yang bermakna antara pendapatan ibu dengan pemakaian AKBK. Dengan demikian hipotesis awal yang menyatakan bahwa ada hubungan yang bermakna antara pendapatan ibu dengan pemakaian AKBK terbukti secara statistik. 


\section{PEMBAHASAN}

AKBK (Alat Kontrasepsi Bawah Kulit) atau dikenal juga dengan istilah implant progestin umumnya berupa kapsul plastik, tipis, fleksibel yang mengandung $36 \mathrm{mg}$ levonogestrol yang dimasukkan kedalam kulit lengan atas wanita. Kapsul ini melepaskan progestin kedalam aliran darah secara perlahan dan biasanya dipasang selama 5 tahun. Mencegah kehamilan dengan cara menghambat terjadinya ovulasi (pelepasan sel telur oleh indung telur), mempertebal lendir mukosa leher rahim, mengganggu pergerakan saluran tuba dan menghalangi pertumbuhan lapisan endometrium. Kontrasepsi ini efektif dalam waktu 48 jam setelah dipasang dan efektif selama 3 tahun.

Penelitian dilakukan di Bidan Praktek Mandiri (BPM) Habiba dengan jumlah populasi penelitian sebanyak 50 responden dengan menggunakan rumus yaitu seluruh populasi dijadikan sampel. Sampel penelitian adalah semua ibu akseptor KB aktif di Bidan Praktek Mandiri (BPM) Habiba yang datanya diperoleh dari rekam medik dan teknik pengambilan sampel menggunakan desain accidental sampling yaitu sebagian dari akseptor KB yang datang berkunjung di Bidan Praktek Mandiri (BPM) Habiba pada saat penelitian berlangsung kemudian data yang telah dikumpulkan diolah dan dilakukan analisis data terdiri dari analisis univariat dan analisis bivariat. Pada analisis dilakukan uji statistik chi-square dengan menggunakan komputerisasi.

Dari hasil penelitian ini didapat bahwa data sebanyak 28 responden $(56 \%)$ berpengetahuan baik sedangkan 22 responden (44\%) yang pengetahuan kurang. Dari hasil uji chi-square diperoleh $\rho$ value $0,011<\square, 0,05$. Hal ini menunjukkan adanya hubungan bermakna antara pengetahuan dengan pemakaian AKBK. Dengan demikian hipotesis awal yang menyatakan bahwa ada hubungan bermakna antara pengetahuan ibu dengan pemakaian AKBK terbukti.

Hasil penelitian hubungan pendapatan akseptor KB dengan Alat Kontrasepsi Bawah Kulit (AKBK) di BPM Habiba Kelurahan Mesat Jaya tahun 2020 data ini diperoleh dari 50 responden. Penelitian ini menggunakan desain cross sectional, maka hanya terbatas mencari hubungan antara variabel independent dan dependent dan kuesioner sebagai alat yang digunakan untuk mengumpulkan data.

Dari hasil penelitian ini didapati bahwa responden yang memiliki pendapatan tinggi berjumlah 19 responden (79\%) lebih kecil daripada pendapatan rendah berjumlah 31 responden $(62 \%)$. Dari hasil penelitian ini menunjukkan bahwa ibu yang berpengetahuan baik sebanyak 11 orang $(20 \%)$, ibu yang berpengetahuan sedang 5 orang $(9,1 \%)$ dan ibu yang berpengetahuan kurang sebanyak 2 orang $(3,6 \%)$.

Dari hasil uji statistik chi-square di peroleh $\rho$ value $0,042<\alpha 0,05$. Hal ini menunjukkan adanya hubungan bermakna antara pendapatan akseptor $\mathrm{KB}$ dengan pemakaian AKBK. Dengan demikian hipotesis awal yang menyatakan bahwa ada hubungan bermakna antara pendapatan akseptor KB dengan pemakaian AKBK terbukti.

Penelitian yang dilakukan Tampubolon \& Tarigan, (2018) menunjukkan bahwa ada hubungan yang signifikan pengetahuan pasangan usia subur dengan penggunaan alat kontrasepsi bawah kulit (AKBK) di lingkungan II Kelurahan Nelayan Indah Kecamatan Medan Labuhan tahun 2017. Hal ini ditunjukkan dengan nilai sig $p=0,002$ maka $p=0,002<$.

Berdasarkan penelitian yang dilakukan oleh Ayu menunjukkan bahwa dari 68 responden yang berpengetahuan kurang adalah 25 orang dan yang berpengetahuan cukup adalah 21 orang dan selebihnya berpengetahuan baik. Kesimpulan penelitian ini 
membuktikan bahwa pengetahuan ibu usia subur memiliki hubungan dengan penggunaan alat kontrasepsi bawah kulit (Ayu, 2013).

Berdasarkan Penelitian yang dilakukan Rina Yulviana menunjukan bahwa ibu yang tidak mendapatkan dukungan suami lebih berisiko 2,2 kali untuk tidak menggunakan AKBK dibandingkan ibu yang mendapatkan dukungan suami dalam penggunaan AKBK (C.I 95\% : 1,267-3,662) (Yulviana, 2017).

Dari hasil penelitian Caruso et al., (2012) didapatkan 31 wanita usia subur, 25 diantaranya melaporkan kehamilan yang tidak terkontrol dan merasa kurang nyaman dalam jumlah anak yang banyak, sedangkan 6 diantaranya tidak melaporkan kehamilannya. Menurut penelitain Neri et al., (2017) efek kontrasepsi yang sangat baik dengan keamanan dan akseptabilitas, terutama dalam hubungan dengan pemeliharaan kualitas hidup yang baik, seksualitas dan penurunan desminore. Keluarga berencana (KB) merupakan salah satu program pelayanan kesehatan preventif paling berperan dalam pengendalian pertumbuhan jumlah penduduk sehingga dapat meningkatkan kesehatan dan kesejahteraan bagi keluarga (Prastika et al., 2019).

Berdasarkan penelitian yang dilakukan oleh Ismi Dzalfa Alfiah tentang faktorfaktor yang berhubungan dengan penggunaan kontrasepsi jangka panjang di wilayah kerja Puskesmas Kalideres tahun 2015. Hasil penelitian menunjukan bahwa tidak sampai separuh responden $(44,4 \%)$ yang pernah disarankan oleh petugas kesehatan untuk menggunakan MKJP. Sementara itu sebagian besar responden diberi kebebasan untuk memilih kontrasepsi yang akan digunakan. Kesimpulan penelitian ini menghasilkan $\mathrm{p}$ value sebesar 1,00 sehingga dapat disimpulkan bahwa tidak ada hubungan yang signifikan antara dukungan petugas kesehatan dengan penggunaan MKJP (Alifah, 2015).

Selain itu, Dukungan suami merupakan suatu bentuk persetujuan dan dorongan yang diberikan oleh suami terhadap suatu pilihan pada suatu objek. Dalam pemilihan dan penggunaan kontrasepsi $\mathrm{KB}$ pada umumnya dan penggunaan kontrasepsi implant pada khususnya dukungan suami serta keterlibatan dalam memutuskan penggunaan kontrasepsi implant merupakan hal yang penting. Hal ini dikarenakan perencanaan keluarga harus ditentukan oleh kedua pasangan agar tidak ada kerugian pada salah satu pihak. Jika ada efek samping atau sesuatu hal yang terjadi akibat penggunaan kontrasepsi tersebut (Yulviana, 2017).

Pemakaian Alat Kontrasepsi Bawah Kulit (AKBK) dipengaruhi oleh banyak faktor. Penelitian tentang faktor yang berhubungan dengan pemakaian kontrasepsi yang dilakukan di Ethiopia didapatkan bahwa pengetahuan dan paritas lebih dari dua mempunyai hubungan yang signifikan terhadap pemakaian alat kontrasepsi. Pengetahuan terhadap alat kontrasepsi pada masyarakat sudah tidak asing lagi terutama pada ibu-ibu mengenai alat kontrasepsi KB tersebut sudah tidak tahu lagi dibicarakan namun pengetahuan yang sudah ada pada masyarakat hanya sebatas tahu, jika mereka merasa perlu lebih tahu mengenai alat kontrasepsi maka mereka akan pergi ke tempat pelayanan kesehatan.

Pengetahuan terhadap alat kontrasepsi pada masyarakat sudah tidak asing lagi terutama pada ibu-ibu mengenai alat kontrasepsi KB tersebut sudah tidak tahu lagi dibicarakan namun pengetahuan yang sudah ada pada masyarakat hanya sebatas tahu, jika mereka merasa perlu lebih tahu mengenai alat kontrasepsi maka mereka akan pergi ke tempat pelayanan kesehatan. Hal ini juga sependapat dengan penelitian yang dilakukan di Tanzania yang menyatakan bahwa pengetahuan, agama, penghasilan, hubungan sosial, daerah perkotaan, komunikasi antara pasangan dan 
informasi dari petugas kesehatan mempunyai hubungan yang signifikan terhadap pemakaian kontrasepsi (Tresnawati, 2012; BKKBN, 2017).

Pengetahuan dalam penelitian ini adalah pengetahuan yang dimiliki oleh responden yang berhubungan dengan $\mathrm{KB}$ yaitu responden mengetahui manfaat $\mathrm{KB}$, jenis alat kontrasepsi, efek samping alat kontrasepsi yang berakibat pada responden, memahami tentang gangguan alat kontrasepsi yang effektif dan yang tidak efektif (Hasmiatin, 2016).

Selanjutnya Tampubolon menyatakan bahwa mayoritas responden menunjukkan pengetahuan yang cukup dan minoritas berpengetahuan baik. Hal ini berhubungan dengan Penggunaan alat kontrasepsi bawah kulit sehingga banyak pasangan usia subur yang tidak menggunakan Alat Kontrasepsi Bawah Kulit (AKBK). Selain dari faktor tingkat pengetahuan informasi juga merupakan salah satu hal yang menyebabkan pasangan usia subur tidak menggunakan alat kontrasepsi bawah kulit, karena walaupun ibu memiliki pengetahuan yang baik akan tetapi tetap saja tidak menggunakan alat kotrasepsi bawah kulit dan lebih memilih alat kontrasepsi lain, pada hal alat kontrasepsi ini sangat efektif dari pada alat kontrasepsi lain seperti pil. Ini sangat mempengaruhi jumlah pasangan usia subur yang menggunakan alat kontrasepsi bawah kulit (AKBK) (Tampubolon \& Tarigan, 2018).

\section{SIMPULAN}

Adanya hubungan yang bermakna antara distribusi frekuensi pengetahuan, pendapatan dan Penggunaan Alat Kontrasepsi Bawah Kulit (AKBK) di BPM Habiba Kelurahan Mesat Jaya Tahun 2020.

\section{SARAN}

Saran dari penelitian ini diharapkan petugas kesehatan dapat lebih meningkatkan informasi kepada seluruh pasangan usia subur yang berkunjung mengenai kontrasepsi dengan memberikan penyuluhan mengenai alat kontrasepsi jangka panjang khususnya Alat Kontrasepsi Bawah kulit (AKB) sehingga dapat meningkatkan jumlah akseptor MKJP.

Selain itu diharapkan dapat mengup-date dan menambah sumber kepustakaan tentang buku-buku, majalah mengenai keluarga berencana dan jurnal kesehatan dan penelitian terdahulu yang berkaitan dengan metodologi penelitian dan biostatisktik yang dapat digunakan untuk melengkapi referensi kepustakaan sehingga dapat menambah sumber penelitian bagi penelitian selanjutnya, serta dapat memberikan informasi dan pengetahuan bagi peneliti yang akan datang dalam meneliti variabel lainnya seperti pendidikan, akses informasi, serta keterbatasan pilihan metode kontrasepsi dan sarana pelayanan yang berhubungan dengan pemakaian kontrasepsi AKBK dengan menggunakan metode-metode penelitian yang berbeda sehingga penelitian mengenai AKBK dapat terus dikembangkan. 


\section{DAFTAR PUSTAKA}

Alfiah, I. (2015). Faktor-Faktor yang Berhubungan dengan Penggunaan Metode Kontrasepi Jangka Panjang di Wilayah Kerja Puskesmas Kecamatan Kalideres Tahun 2015. Universitas Islam Negeri Syarif Hidayatullah Jakarta

Ambarwati, E. R. (2011). Asuhan Kebidanan Komunitas. Yogyakarta: Nuha Medika

Anggraini, Y., \& Martini, M. (2012). Pelayanan Keluarga Berencana. Yogyakarta: Rohima Press

Ayu, A. (2013). Hubungan Pengetahuan Ibu Usia Subur tentang Alat Kontrasepsi Bawah Kulit dengan Tingkat Penggunaan Alat Kontrasepsi Bawah Kulit di Klinik Rehulina Br Sitepu Desa Bandar Khalifah pada Tahun 2013

Badan Pusat Statistik. (2015). Hasil Sensus Penduduk 2015, Data Agregat per Provinsi. Jakarta

BKKBN. (2017). Laporan Kinerja Instansi Pemerintah 2016 Badan Kependudukan Dan Keluarga Berencana Nasional, 1-102

BKKBN. (2020). SDKI Capaian Penggunaan Kontrasepsi 2017

Caruso, S., Malandrino, C., Cicero, C., Ciancio, F., Cariola, M., \& Cianci, A. (2012). Quality of Sexual Life Women on Oral Contraceptive Continued Regimen : Pilot Study, 460-66. J Sex Med, 10(2), 460-6. doi: 10.1111/j.1743-6109.2012.03004.x

Dinas Pengendalian Penduduk Keluarga Berencana. (2019). Kota Lubuklinggau

Hartono, H. (2010). Keluarga Berencana dan Kontrasepsi (KB). Jakarta: Pustaka Sinar Harapan. http://aminulaprijal.byethost24.com

Hasmiatin, H. (2016). Hubungan Pengetahuan, Dukungan Suami dan Budaya dengan Penggunaan Alat Kontrasepsi Implant pada Pasangan Usia Subur di Wilayah Kerja Puskesmas Abeli Kecamatan Abeli Kota Kendari Tahun 2016. http://sitedi.uho.ac.id/uploads_sitedi/F1D311072_sitedi_skripsi.pdf

Kusmiran, E. (2011). Kesehatan Reproduksi Remaja dan Wanita.. Jakarta: Salemba Medika. www.lactamilmama.com/Masa-Subur

Manuaba, M., \& Ida, B. G. (2011). Ilmu Kebidanan, Penyakit Kandungan dan KB. Untuk Pendidikan Bidan. Jakarta : EGC

Neri, M., Piras, B., Paoletti, A. M., Vallerino, V., Corda, V., Ronchetti, C., Taccori, V., Pilloni, M., Zedda, P., Capobianco, G., Dessole, S., Melis, G. B., \& Mais, V. (2017). Long-Acting Reversible Contraception (LARC) with the Intrauterine System with Levonorgestrel $(6 \mathrm{Mcg} / \mathrm{D})$ : Observational Study on the Acceptability, Quality of Life, and Sexuality in Italian Women. Gynecological Endocrinology, 34(6),532-535. https://doi.org/10.1080/09513590.2017.1416465

Padila, P. (2015). Asuhan Keperawatan Maternitas 1. Yogyakarta : Nuha Medika

Prastika, B. P.S., Armini, N. K. A., \& Pradanie, R. (2019). Hubungan Dukungan Suami dan Gaya Hidup dengan Kualitas Hidup Akseptor KB IUD di Wilayah Kerja Puskesmas Mulyorejo Surabaya. Universitas Airlangga

Septianingrum, Y., Wardani, E. M., \& Kartini, Y. (2018). Faktor-Faktor yang Mempengaruhi Tingginya Akseptor KB Suntik 3 Bulan. Jurnal Ners dan Kebidan, $5(1)$,

15-19. https://doi.org/10.26699/jnk.v5i1.ART.p015-019

Tampubolon, I. S., \& Tarigan, J. (2018). Hubungan Pengetahuan, Dukungan Suami dan Petugas Kesehatan dengan Penggunaan Alat Kontrasepsi Bawah Kulit (AKBK) pada Pasangan Usia Subur di Lingkungan II Kelurahan Nelayan Indah Kecamatan Medan Labuhan. Jurnal Bidan Komunitas, 1(2), 59-66. http://ejournal.helvetia.ac.id/index.php/jbk 
Tim Pokja SDKI DPP PPNI. (2017). Standar Diagnosis Keperawatan Indonesia Definisi dan Indikator Diagnostik. Jakarta: Dewan Pengurus PPNI

Tresnawati, F. (2012). Asuhan Kebidanan. Jakarta: Prestasi Pustakaraya

Yulviana, R. (2015). Faktor-Faktor yang Berhubungan dengan Penggunaan Alat Kontrasepsi Bawah Kulit di Kecamatan Payung Sekaki Kota Pekanbaru Tahun 2015. Jurnal Penelitian dan Kajian Ilmiah, 11(75), 122-7. https://jurnal.umsb.ac.id/index.php/menarailmu/article/view/158 